\title{
Becoming anthropological: a cultural biography of EL Mitchell's photographs of Aboriginal people
}

\author{
Joanna Sassoon
}

\section{Introduction}

As a form of documentary evidence, photographs are complex and challenging. They are a material representation of a frozen moment in time, but what they are of is only one of the many possible meanings that encircle them as a photographic object. This complexity is reflected in debates about the sources of photographic meaning which have shifted from a focus on content alone to analysing interactive relationships between image content and the photographic object's context. While John Tagg sees that it is the 'discursive system' in which a photograph is embedded that contributes to its meanings, ${ }^{1}$ this paper explores individual actions and institutional practices behind the placement of photographs in specific contexts which then frame photographic meanings. ${ }^{2}$

Along with debates about the sources of photographic meaning, there has been further exploration of the nature of the photograph as an 'original' object. Whereas a photograph was once seen as a singular item, this paper builds on Joan Schwartz's argument that they are one of many multiple originals produced from a single negative, each with their own meaning emanating from the contexts in which they are found. ${ }^{3}$

As Igor Kopytoff has argued, in order to understand objects it is necessary to look at their life history through the cycles of production, exchange and consumption. ${ }^{4}$ What constitutes the extent of the life of an object is open to debate. This paper follows ideas developed in recent life histories of photographs. ${ }^{5}$ In a similar vein to an object which 'becomes rubbish' when it is discarded later 'becoming archaeological' on rediscovery, this tracks a 'long life history' of a group of photographs of Aboriginal people by the Western Australian commercial photographer EL Mitchell from their time of taking to the present. Combining a long life history of a photographic image with the idea that

\footnotetext{
Tagg 1988: 4 .

Edwards 2001.

Schwartz 1996.

Kopytoff 1986.

For example, see Pinney 1997 and Poole 1997.
} 
there are multiple original photographs containing the same image opens up new ways of tracing how photographic meanings accrue according to the contexts in which they are found.

This is a cultural biography. It recognises that 'at the heart of the notion of biography are questions about the links between people and things; about the way meanings and values are accumulated and transformed'. ${ }^{\prime}$ In taking the 'long life history' approach to a study of a group of photographs, this paper follows the idea that the life of an object continues beyond its original purpose of creation. ${ }^{7}$ As Arjun Appadurai wrote:

We have to follow things themselves, for their meanings are inscribed in their forms, their uses, their trajectory. It is only through the analysis of these trajectories that we can interpret the human transactions and calculations that enliven things. ${ }^{8}$

What the marketplace and researchers do with and to photographs is only part of the many relationships across the ongoing lives of the objects. What happens to photographs once they enter cultural institutions is another part of their life that influences the way they may be understood in future. Thus, the lives of materials are in the hands of human agents, many of whom remain anonymous under the cover of institutional practice. This paper analyses the long lives of multiple original photographs from their production, through their ongoing consumption, and to their preservation, and interrogates the role cultural institutional practices play in the ongoing life histories of photographs.

The challenges at the core of this paper are twofold. One rests with the moments when institutional practices fix a single label to a photograph which over its life has accrued a plurality of meanings. The other argues for an equal status for photographs with other forms of material culture, and for this to be translated into institutional practice. ${ }^{9}$ Many of Mitchell's photographs of Aboriginal people have 'become anthropological' over time through the way they have been consumed and the manner in which they were circulated and exchanged. ${ }^{10}$ They have equally 'become anthropological' through institutional practices that surrounded them at their point of preservation and which influence their new trajectories. While this does not change the material nature of the photograph, this paper shows the cultural processes by which a group of photographs of Aboriginal people 'become anthropological' at particular points in their lives, and investigates ways in which this meaning has become ascribed.

\section{The photographs}

The photographer EL Mitchell first visited Australia with his family from Bradford, UK as a young child for about five years from 1884. He migrated to Australia in 1899 aged 23 where, for the next ten years, he moved between Sydney, rural New South Wales and Queensland eking out his living from photography. After several years taking pho-

6. Gosden and Marshall 1999: 171.

7. For example see Gosden and Marshall 1999, Holthorf 2002, Poigmant 1993

8. Kopytoff 1986: 5 .

9. Porter 1989.

10. Edwards 1992: 13; Poole 1997. 
tographs across Western Australia he opened a studio in Perth in 1912/13 which he operated until the Depression forced its closure in 1931. His transition from itinerant, migrant photographer in New South Wales to international image-maker of Western Australia and official photographer to the Governor of Western Australia is a story that shows the intersection of the nature of his photographs with political agendas at a specific moment in Western Australian and Australian history. It is also a story of international distribution networks for his photographs, about the relationship between Mitchell as a man of empire and the imperial vision contained within his photographs, and a trade across the British empire within which his photographs became enmeshed. ${ }^{11}$

Several thousand topographical, portrait, rural, urban, sporting and industrial photographs provide evidence of Mitchell's travels through New South Wales, north Queensland and Western Australia during his photographic career. Amongst this work are approximately 200 photographic prints, negatives, lantern-slides and published reproductions of Aboriginal people taken in distinct phases of his professional life. While their subject is Aboriginal people, they neither portray a homogenous picture of life over the period in which he was photographing, nor were they all taken under the same commercial conditions.

Mitchell's first known photographs of Aboriginal people taken between 1907 and late 1908 are from the northern Atherton tablelands region in Queensland. ${ }^{12}$ He photographed Aboriginal people in a range of active contexts including coffee picking, spear fishing, dancing, and near their dwellings. It is likely they were taken as a speculative venture; some were published in the pictorial newspaper the Queenslander, and much later they appeared in adventure narratives. After Mitchell moved to Western Australia these photographs were published in the pictorial newspaper the Western Mail although their geographical specificity was lost from the captions. His photographs of Aboriginal people in Western Australia were taken in distinct phases and geographical zones. The changes in their content and style reflect some of the political contexts surrounding the lives of Aboriginal people and the shift in the nature of his photographic practice from speculative ventures towards commissioned works. Equally, these changes are likely to reflect his own ideas relating to Aboriginal people as he moved from travelling in northern Western Australia to being based in metropolitan Perth.

His first series from northern and eastern regions of Western Australia are dated between 1908 and 1912. Unlike his Queensland photographs there are very few that survive showing hunting and gathering activities, but his Aboriginal subjects stand in more passive poses, demonstrating, and at times recreating, aspects of culture for the viewer. They are enslaved within prisons or in chains, standing outside 'humpies' or displaying visible signs of leprosy. His northern photographs show his desire to represent a pre-contact and pristine notion of Aboriginality in order to record a 'dying culture', and his work in Southern Cross bears influence of earlier anthropometric pho-

11. For a more detailed discussion of the intersection between his life and the lives of his works, see Sassoon 2001.

12. These dates are estimates from a combination of dated Masonic Lodge cards which show his movements, and publication dates of his Queensland photographs in relation to the first publication of his later Western Australian photographs. 
tographic traditions of Huxley. ${ }^{13}$ Like his topographic work of this time, it is probable his Aboriginal photographs were taken as speculative ventures. ${ }^{14}$ Photographs from his early series of Aboriginal people in Western Australia were first published from late 1909 and, although the majority were taken by 1911, they were repeatedly published in the Western Mail until the early 1920s, to set the 'savage' against 'civilisation' for an imperially focussed readership (Figure 1). Over time a selection of these works was widely disseminated across a range of published formats including postcards, books, encyclopedia and government publications.

Once he had established his studio in the Perth metropolitan area, Mitchell did not photograph Aboriginal people for over ten years. This silence is similarly noted in art of the period, ${ }^{15}$ and is likely a reflection of contradictory policies of assimilation and isolation of Aboriginal people. ${ }^{16}$ For example, while he had clients including the New Norcia Mission who had responsibility for the lives of Aboriginal people, it seems their commissioned photographs of mission activities did not include Aboriginal people as they had done in the $1860 \mathrm{~s} .{ }^{17}$ In the South-West where he travelled extensively for topographic and industrial commissions, Aboriginal people were for the most part 'out of sight, out of mind' in reserves often a comsiderable distance from the major wheat-belt farms that he was photographing. Aside from issues of compliance with being photographed, access to the reserves to photograph Aboriginal people would have required official permission, and it is unlikely that his major clients - government, private landholders and the newspapers - would have purchased such photographs.

There are only two sets of photographs of Aboriginal people that Mitchell is known to have taken once he opened his studio in Perth, both of which were created under contract. Firstly, in 1918 he was commissioned by the Western Mail to photograph an exhibition corroboree organised specifically for the visit of the French Mission to Western Australia. In style these photoggraphs show more formal poses designed to highlight aspects of the public ceremony and the physicality of the people carefully selected for the occasion to reinforce theirr primitive condition. Cropped versions of this series were published in school texts and adventure narratives. Secondly, he created a set of photographs of the Moore River Mission in the early 1920s (Figure 2). These negatives became part of the Government Print photograph collection, and were likely to have been taken under contract for the Aborigines Department. This set included streetscapes, interiors, group photographs, and views of activities at the Mission, and is clearly supportive of the contemporary palliative and assimilation policies of government. Photographs from this series were published in the Western Mail and received widespread use in government publications. More recently they have been placed in exhibitions which include the Western Alustralian Museum Indigenous exhibition Katte Djinoong, and formed the basis for screen 1 -sets for the film Rabbit-proof fence.

13. Edwards 1997.

14. For a discussion of his topographic work in the north-west of Australia see Sassoon 1999.

15. Gooding 1987.

16. For a history of the experiences of Aborigiinal people in Australia see Haebich 2000.

17. Hutchison 1995. 

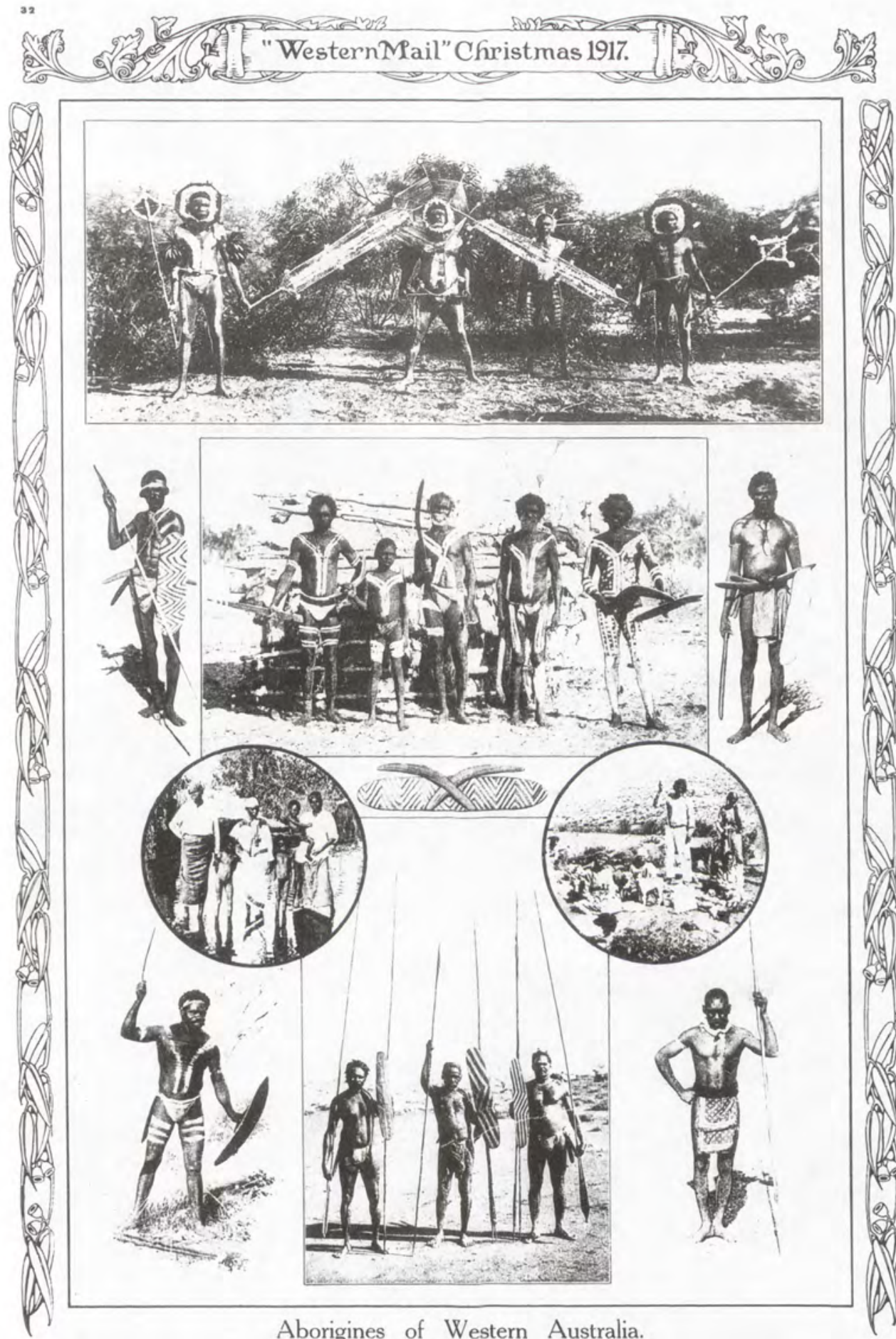

Figure 1 EL Mitchell. 'Aborigines of Western Australia'. Western Mail Christmas 1917 

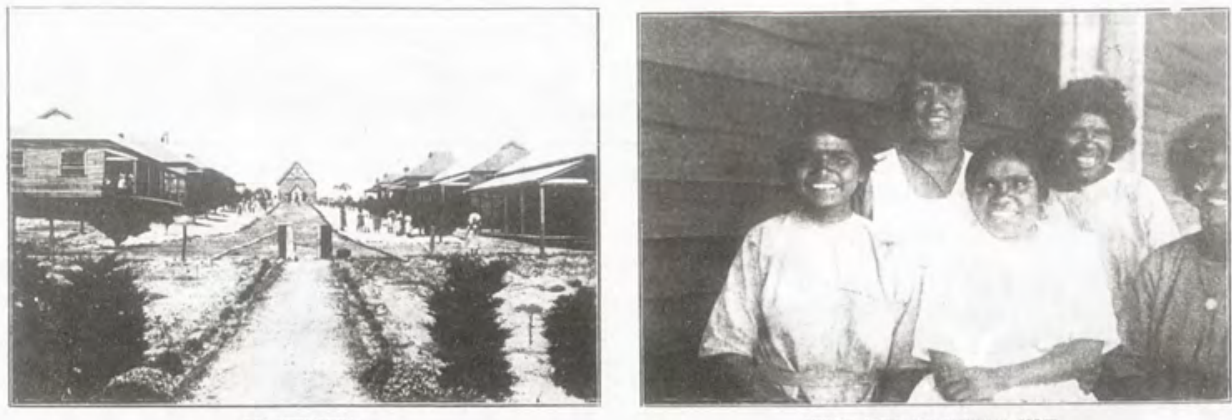

THE sertirmewr
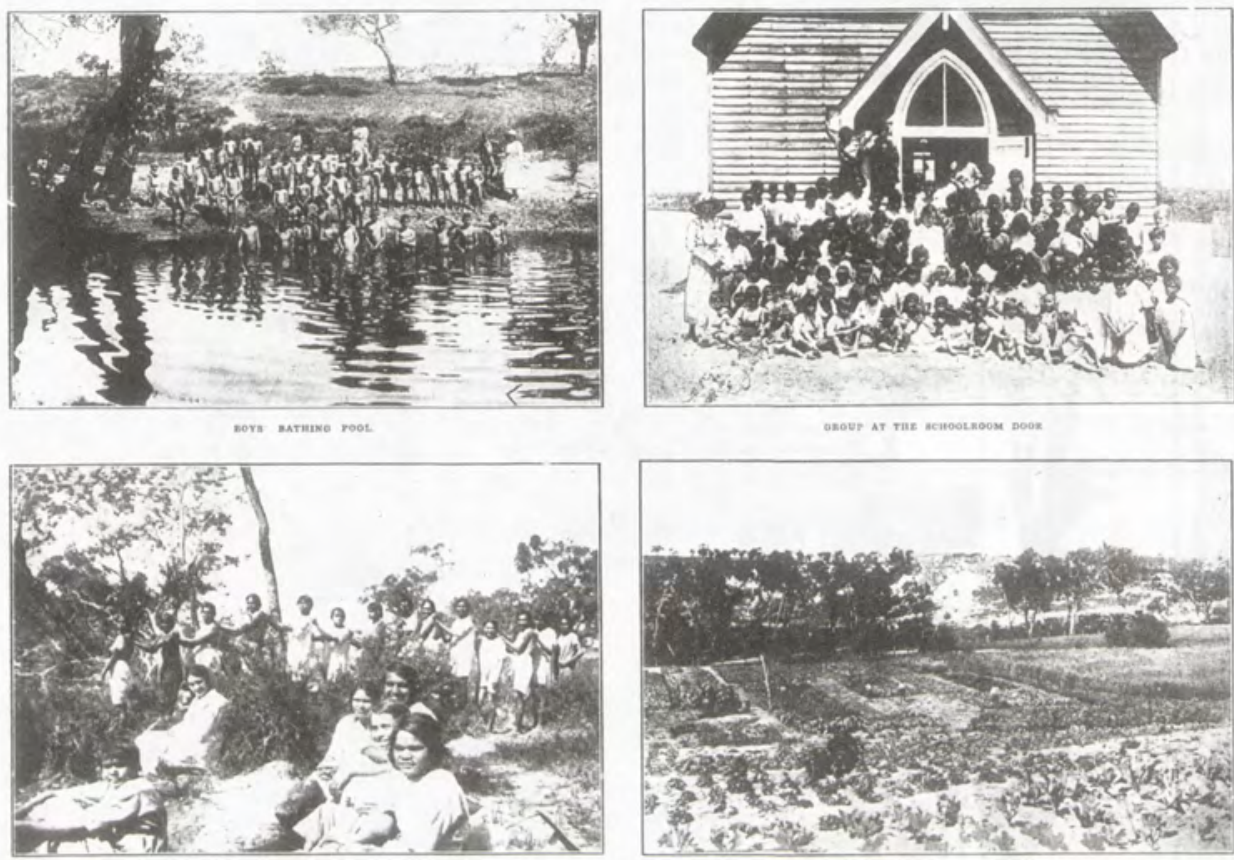

marm aminoep
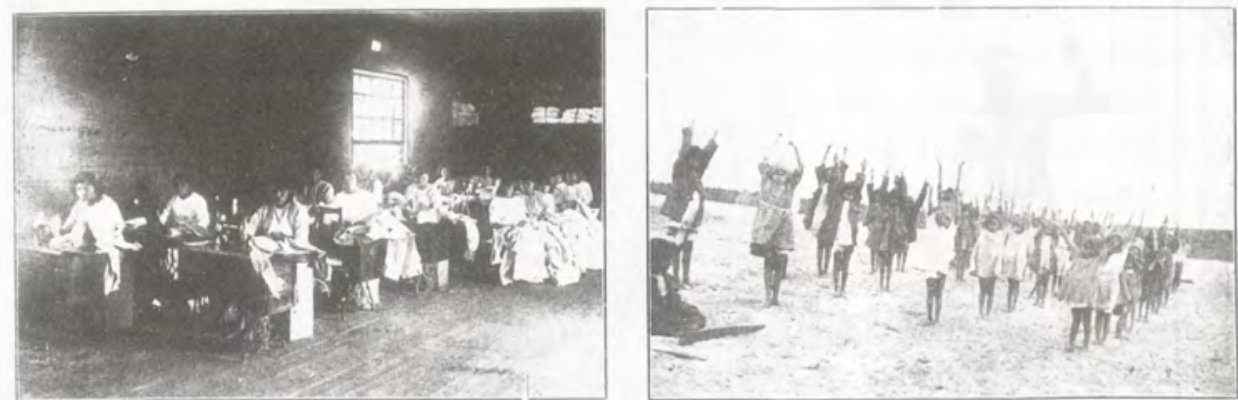

Scenet at the Moore River Settement

Figure 2 EL Mitchell. 'Scenes at the Moore River Settlement' Western Mail 8 November 1923 


\section{Serving anthropology}

Mitchell's photographs of Aboriginal people were created as speculative commercial ventures or were specifically commissioned. The only direct textual source for Mitchell's intended meanings of the photographs survive through captions he inscribed in the image area of his works. On occasions these texts reveal the geographical origins of the people, while the rhetoric of captions such as 'Queen' and 'Beauty' show his awareness of how to use captions to shift photographs taken within the conventions of ethnographic photography to become popular postcards. ${ }^{18}$ More broadly, Mitchell's photographs reveal his interest in the physical nature and form of the body of Aboriginal men and occasionally women. However, while his representations echo some of the contemporary styles of photographs in circulation, the settings in which he photographed people at times visually confuse the picture and can be seen as a metaphor for his own ambiguities of stylistic adherence. For example, some photographs specifically focus on the physical nature of body cicatrices, though these are posed against vegetation giving a variegated background against which it is hard to see the body (Figure 3). In another series, he photographs people posed in classical mock fighting stance, thus representing ideas relating to Aboriginal 'native primitivism', while the models he chose often conformed to a classical notion of the 'body' (Figure 4).

Mitchell's photographs are a rich source of ethnographic information as they show clear details of artefacts such as shields, spears, boomerangs and headdresses. They provide cultural information for those with knowledge of its interpretation, though Mitchell himself did not record this information on his negatives or prints. The tone of his captions and their pictorial style suggest that they were not taken with anthropological intent, nor were they created as part of expeditions, and most circulate outside the strict discourse of anthropology. In spite of not being created specifically to produce anthropological information, the photographs contain features which have made them attractive for anthropological uses almost from the time they were taken.

The content and style of Mitchell's photographs were contiguous with the dominant political ideologies of the time. In a kind of visual apartheid, his photographs of Aboriginal people outside their dwellings show their isolation from any European structures, and thus reflect the clear separation of community spaces at the time. Equally, he rarely photographed Aboriginal people alongside Europeans, and these photographs are taken in specific situations where the structures of racial difference and social and disciplinary control are particularly well defined, such as in gaols. In these photographs, Mitchell often used strong perspective lines to emphasise the colonial context he was photographing, and the clear sight lines leading the viewer through the photographs serve both to involve the viewer in the image and to reinforce power structures (Figure 5). Thus, through looking at broad patterns, it is possible to see that Mitchell's photographs comply with and serve to reinforce the dominant government policy that Aboriginal people be separated from the rest of society.

While investigating why Mitchell's representations are as they are, it is as important to note what is absent from his photographs as what is present. In contrast to many 


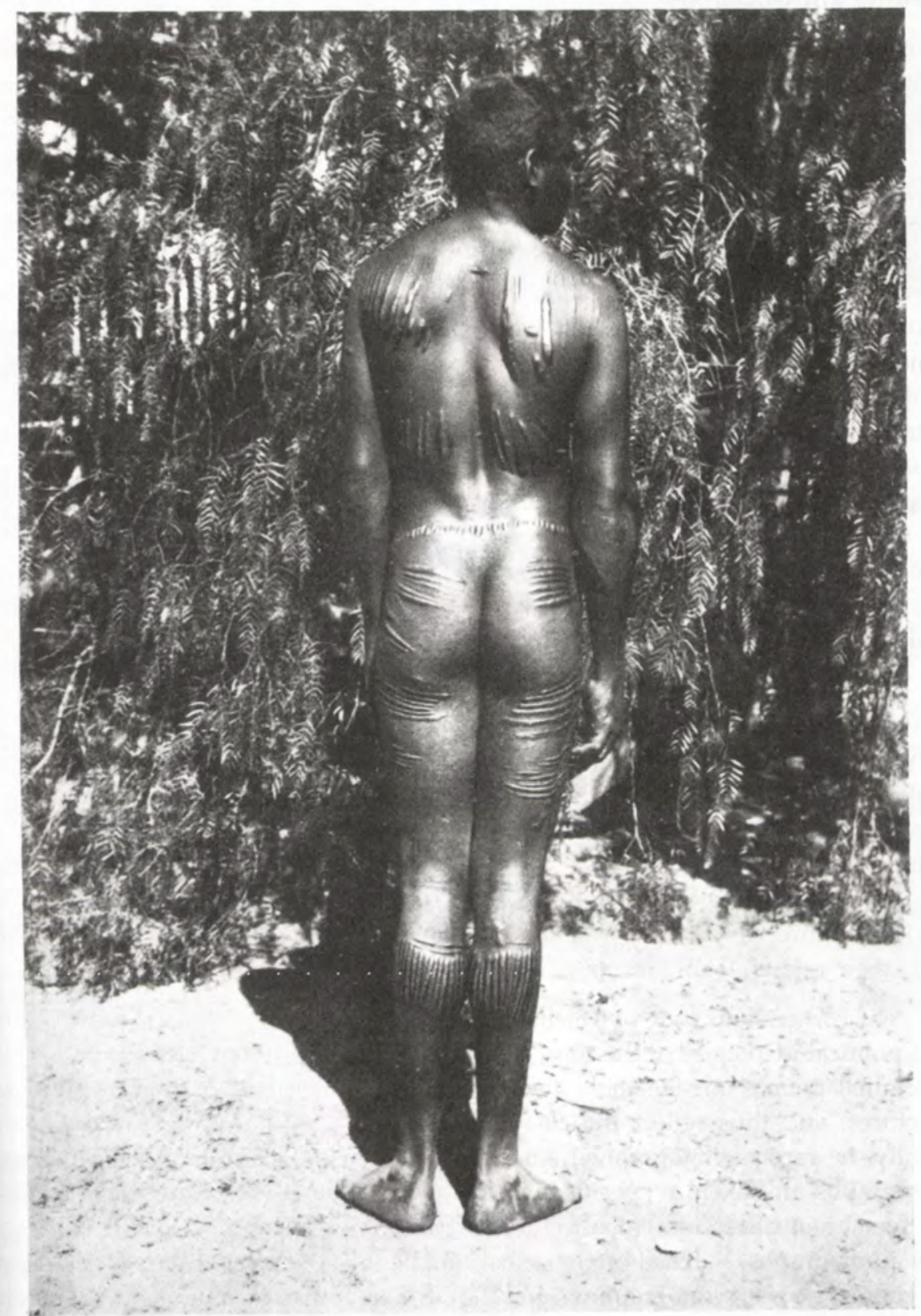

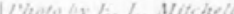

Body scarring for ornamentation - a Kimberley native. " He explained that these had been made by his 'Dadda' with a glass-bottle knife.

(See page 121).

PLATE XVIII.

Figure 3 EL Mitchell. 'Nor-West native' c1909. Published in Porteus 1929 with the caption 'Body scarring for ornamentation - A Kimberley native. "He explained that these had been made by his 'Dadda' with a glass-bottle knife."' 

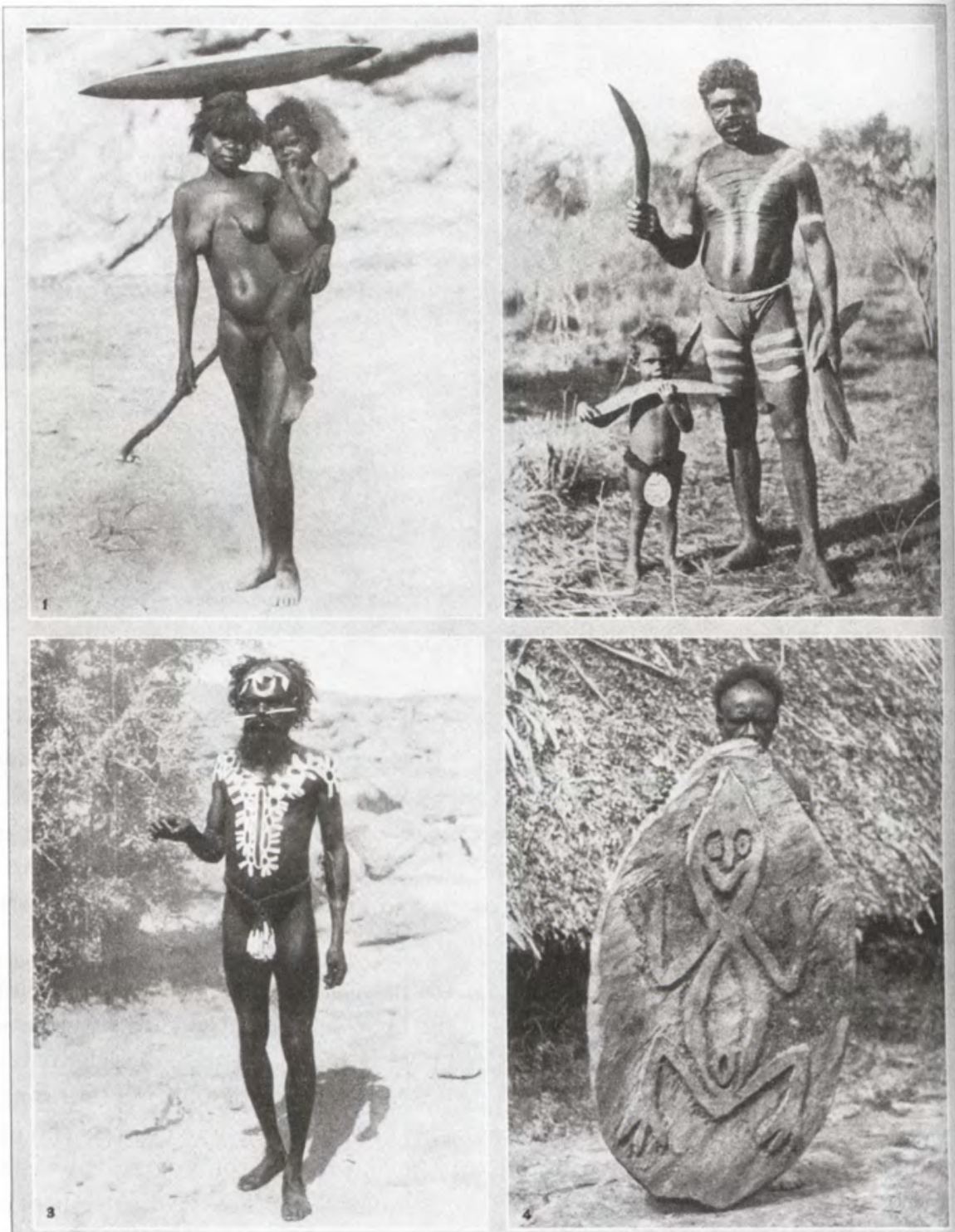

TYPES OF AUSTRALIAN ABORIGINES

1. Arunta woman and child. The mother is going out into the scrub in search of seeds and roots for food, carrying a digging stick in one A Broome native

3. Arunta medieine man, showing the erunchileha or "devil's hand" at centing the Eruncha of "evil one"

4. Wooden image from the "Devil Devil House" which the natives belier Dotects them frem ghosts and other wevil spirits

Figure 4 EL Mitchell 'Nor'West natives' c1909. Published in Encyclopedia Britannica 1929 with page caption 'Types of Australian Aborigines'. Top right photograph with the caption 'A Broome native and his child with boomerangs, the aboriginal weapon, in their hands.' 


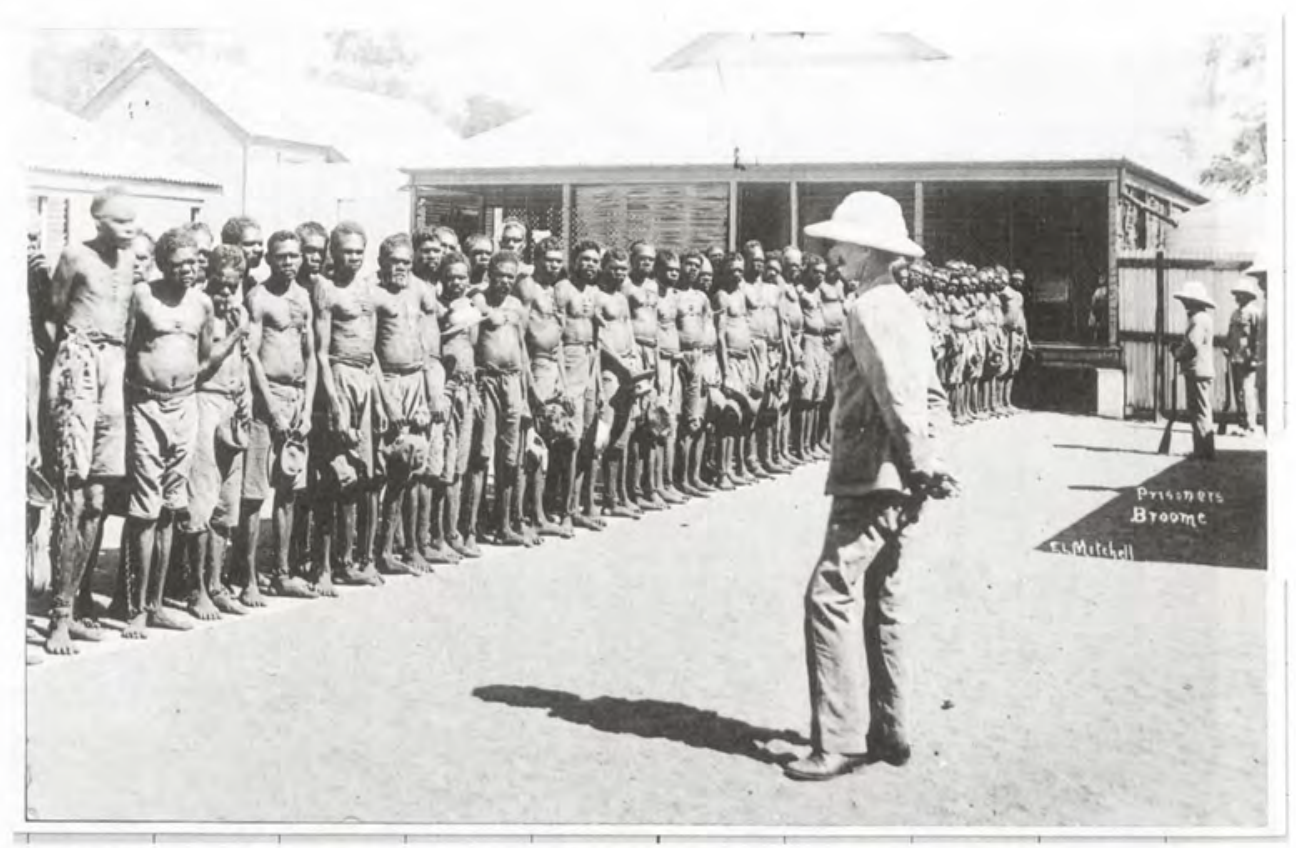

Figure 5 EL Mitchell. 'Prisoners Broome' c1909. Western Australian Museum

taking photographs during this time, Mitchell does not appear to have photographed Aboriginal people of mixed descent, nor people living on the periphery of towns and cities or on reserves, preferring to concentrate on what was colloquially known as the 'pristine and primitive full-blood'. Likewise, no photographs survive showing Aboriginal people in the domestic work environment, similar to those which survive in private collections, nor did he appear to take commissioned studio portraits of Aboriginal people wishing to show their successful assimilation into broader society. ${ }^{19}$

An absence of specific details of place or names of the subjects of the photographs, and his focus on the 'primitive' aspects of the body and material culture, lends support to the notion that Mitchell saw Aboriginal people more as a type or race than as individuals. In this sense, the way in which he posed and captioned his photographs served to shift the readings of the Aboriginal subjects to becoming mere objects. The nature of their content and the style of representation meant that his photographs were suitable for extensive use by government, ${ }^{20}$ and were equally able to serve the needs of contemporary anthropology.

\section{Becoming anthropological}

Mitchell's photographs of Aboriginal people were clearly a commercial success, with many of his works first published in the popular press (Figure 1). In the first ten years of their life, and while they remained ostensibly under the control of the photographer,

19. For examples of the family and commercial photographs showing a broad range of contexts and experiences see Haebich 1988; Tilbrook 1983; Aird 1993.

20. See for example Western Australia, Immigration and Tourist Department 1912; British Association 1914; Anonymous 1920. 
these photographs received wide currency in a range of contexts including the popular press, government and commercial publications, and tourist and missionary postcards. Through these many contemporary uses they became a formative influence on how a wide variety of local and international audiences envisioned Aboriginal people. The contextual message of most of these uses was consistent - Aboriginal people were either too primitive to survive, or were in need of missionary and government assistance to 'smooth the dying pillow'. Over time, multiple original prints were moved from the control of the photographer and into state and federal government photograph collections housed in Australia and across the British empire, which has enabled international access to this material. Consequently, the meanings of many of these photographs have changed since they were first taken as they have moved across a wide range of published genres and contexts.

While there is no evidence that Mitchell was employed to take photographs on, or that he even accompanied, formal anthropological expeditions, it did not take long for some of Mitchell's work to 'become anthropological' through their incorporation in the products of anthropological fieldwork. September and October 1910 saw two leaders of international anthropological expeditions competing for space in the local newspaper. The Swedish zoologist Eric Mjoberg stopped in Perth during his expedition which took in both Queensland and Western Australia, and which was both ethnographic and zoological in its focus. While the Mjoberg expedition produced some of its own photographic records, ${ }^{21}$ publications that resulted from this expedition contain photographs derived from a range of photographers, including EL Mitchell. ${ }^{22}$ The Cambridge University Ethnology expedition similarly combined natural science and anthropology. Its leader was the anthropologist Radcliffe Brown, its British expeditioner EL Grant Watson a biologist, and its local ethnographer was Daisy Bates. Aspects of the expedition's story, which have become the stuff of legend, have been told elsewhere. ${ }^{23}$ In itself, the Cambridge Expedition produced little visual data of record. However, while Mitchell did not accompany either expedition, photographs taken by him first 'became anthropological' through their use in formal and informal publications that emerge from those associated with these expeditions.

Daisy Bates sold written work to the Western Mail amongst other publications. ${ }^{24}$ Much of the Western Mail format includes illustrations and texts running parallel and there are only occasional insights into how the editor constructed articles around access to specific photographs. In one letter from the editor to Bates it was suggested:

I have four views of the Wilgie Mia Mine. I think you could write a good article about it ... I am sending the views with this letter and will be glad to have the article as soon as possible. ${ }^{25}$

21. These are held in the Australian Museum in Sydney.

22. Mjoberg 1915.

23. White $1980 / 81$, Hodge 1992.

24. For a listing of her newspaper articles, see the National Library listing of the Daisy Bates collection, NLA MS365.

25. Letter Robertson to Bates, 30 April 1908 Daisy Bates collection, NLA MS365 97/587. Most of the extant photographs of Wilgia Mia were taken by W Kretchmar. 
While it is not clear if Bates and Mitchell ever met, the newspaper published some of her written work in association with his photographs which he likewise sold to the newspaper. Bates was clearly attracted to Mitchell's work, and she preserved newspaper cuttings of Mitchell's published photographs which were acknowledged to him and the same photographs are found in both their collections. ${ }^{26}$ Whatever the process behind their common placement in the newspaper, the combination of Mitchell's photographs with Bates' texts presented a powerful message relating to the 'last remnants of a dying culture'.

Embedded by association with Daisy Bates through her articles in the Western Mail, Mitchell's photographs were also used to create a sense of the period in the posthumous publication of her major work The native tribes of Western Australia. ${ }^{27}$ As part of the research for illustrations to include in this work, the editor Isobel White made an effort to use photographs with which Daisy Bates was familiar, or which were contemporaneous with her Western Australian sojourn. For example, in one letter to the Battye Library in Perth, the National Library wrote that:

Mrs Bates published numerous articles in the Western mail, many of which were illustrated with photographs taken by E.G. Rome, E.L. Mitchell, C.E. Farr and others. Many of these photographs relate directly to people and events described in The native tribes of Western Australia, and we are therefore anxious to include them in the book. ${ }^{28}$

Thus, it was through evidence of the photographs' prior associations with Bates' popular articles preserved in her archive, that Mitchell's work later became anthropological to lend an air of authenticity to Daisy Bates' text.

Over time, the quality of Mitchell's work received recognition through its exposure in publications in Western Australia and, in the absence of a formal government photographer in Western Australia until 1929, he was its main de-facto. ${ }^{29}$ To fulfil an international demand for images of Australia, and to service the political needs of the immigration imperative, Mitchell supplied multiple original prints for placement in official government photograph collections. From the Western Australian and Commonwealth government collections, his work spread through official international networks to the Agent General for Western Australia, and through the Commonwealth Immigration Office collections in Melbourne to the Australian High Commission in London and its consulate in New York. Thus the international trajectory which enabled the ongoing lives of these photographs was created.

Mitchell's photographs moved into the sitting rooms and minds of the children of the British empire through the translation of the output of anthropological expeditions into an adventure narrative, and their seepage into school textbooks. ${ }^{30}$ Designed for older children, EL Grant Watson published in Britain an account of his adventure on Radcliffe Brown's expedition as With the Aborigines, a part of a series on travel and exploration produced by George Philip. ${ }^{31}$ Written with 20 years hindsight, this account

26. For example Daisy Bates collection, National Library NLA MS365/94.

27. White 1985.

28. NLA to Battye Library 29 April 1982. National Library internal publication files.

29. Sassoon 2004.

30. For example see Browne 1929. 
becomes the site of adventure where 19th century colonial attitudes are reiterated for the next generation of empire builders. While the specific output of the Radcliffe Brown expedition was visually barren, ${ }^{32}$ Watson's publication incorporates photographs by Mitchell which provide a citation to the original expedition, and reflect racial attitudes of that period. To authenticate the experience of being there, and to enhance the text for an imperial audience, the book is illustrated with caricatures whose themes and compositions derive in part from Mitchell's photographs. In what may be a coincidental echo back to the personnel on the expedition, Watson selected photographs which shared common authorship with those used by Bates in her articles. Watson's source of the photographs was the Australian High Commission in London, which made available officially sanctioned images of Australia for migration and propaganda purposes. The placement of Mitchell's work in this collection shows the extent of the access to, and circulation of, his work across the empire, as well as the empire's desire for this kind of imagery.

How Mitchell's original captions for the photographs were rewritten in the international context reveals the nature of the official image-making of which they were part, as well as how they were organised and retrieved (Figure 6). For example, originals of one photograph survive with Mitchell's caption 'Nor'West natives'. Once in the Commonwealth Immigration Office, the caption on the back returned the photograph to a generic image of an 'Australian Aborigine', and another original held in the Exclusive News Agency collections, which originally came from the Commonwealth collections, was filed under 'Australasia-Australia-Types-Aborigines-men'. Thus from its original regional ascription, one photograph became a generic national symbol in the hands of the Commonwealth, and another was placed within the domain of physical anthropology. Simply re-writing captions is one demonstration of how different contexts can frame the meanings of multiple originals of the same photograph.

The year 1929 was an important one for Mitchell's photographs and provides evidence of how the dissemination of multiple originals resulted in his material becoming anthropological'. One photograph was published in association with three taken by Spencer and Gillen as a full page plate in the entry relating to Australian Aborigines in the co-ordinate of imperial knowledge, the Encyclopedia Britannica (Figure 4). This photograph was obtained from the London based Australian High Commission collection, and the caption printed in the encyclopedia suggests the specific original print acquired had a more geographically specific caption 'A Broome native ...' than that originally ascribed by the photographer 'Nor'West natives'. Two years later, a selection of Mitchell's photographs was published in an anthropological text resulting from an internationally funded expedition to the Kimberley. Stanley D Porteus' work The Psychology of the primitive is illustrated with a mosaic of photographs from commercial photographers alongside amateur snapshots taken during fieldwork. ${ }^{33}$ Amongst the 70

31. Watson 1930.

32. Only a few of Radcliffe-Brown's Australian lantern-slides have been traced to the Pitt Rivers Museum in Oxford. There are no Mitchell photographs amongst this collection which is predominantly from Kerry Studios.

33. Porteus 1931. 


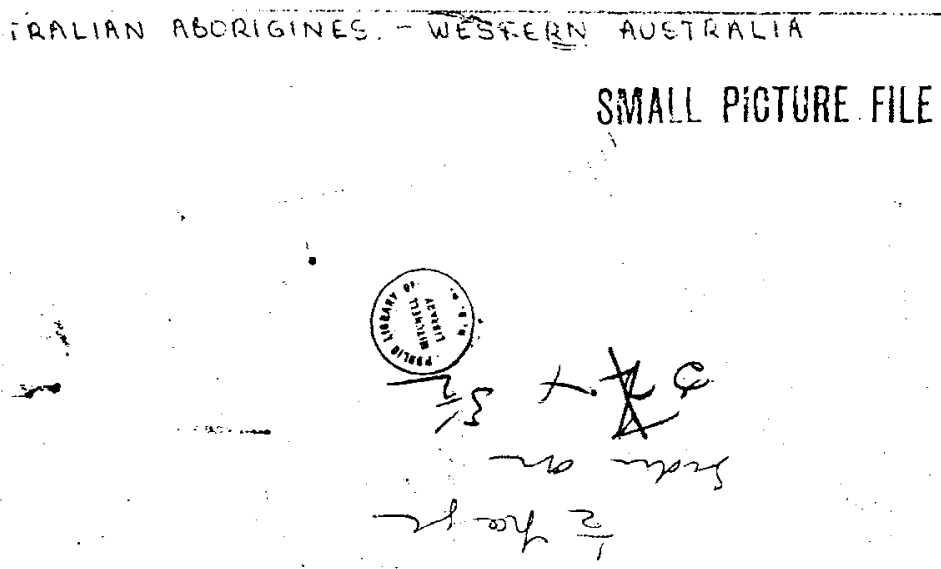

\section{6}

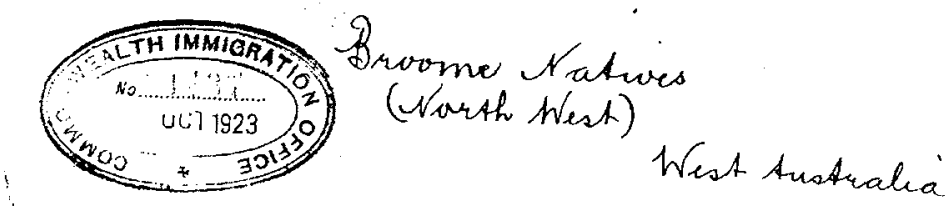

Figure 6 EL Mitchell. 'Nor-West natives' c1909. Back of Commonwealth Immigration Office no 1437. State Library of New South Wales

photographs reproduced in this book, seven are attributed to Mitchell, though only four were definitely taken by him (Figure 3).

The mix of photographs attributed by Porteus to Mitchell, though not necessarily taken by him, are similar to those appearing in an album of Aboriginal photographs created by Mitchell. It is highly likely that Porteus obtained copies of Mitchell's photographs directly from the photographer when he visited Perth. However, there remains the possibility that Porteus had been introduced to Mitchell through AO Neville, then Protector of Aborigines, and surrogate controller of anthropological research in Western Australia. Neville was himself a collector of photographs of Aboriginal people. ${ }^{34}$ Porteus sought to define the status of Aboriginal people on the hominid evolutionary scale. His work combines a racy adventure narrative under the patina of science, and frames Aboriginal people as primitive through the use of then outdated psychological and physical tests. His selection of photographs, in particular of scarified bodies, serves to reinforce this picture of 'the primitive' and his use of captions ensures this message is clearly communicated to the reader. Porteus captions one photograph with a fictitious explanation in order to create the impression that 'he was there' when the photograph was taken. Mitchell's original caption in the image area was 'Kimberley native'. Por-

34. Gray 1997, 1988; Leslie 1993. 
teus' caption contains echoes of this and reads: 'Body scarring for ornamentation - a Kimberley native. "He explained that these had been made by his 'Dadda' with a glassbottle knife." 35 Without knowing that the photograph was taken at least seventeen years prior to Porteus' expedition to Australia, the caption is an effective device in creating an impression of an ethnographic present.

\section{Mitchell's own framing mechanisms}

The way material is managed in cultural institutions is central to framing their ongoing meanings, and documentation styles have a profound effect on the research potential of material. In essence, such practices become a sign for the manner in which such institutions value and understand photographs. As Holtorf writes 'The material identities ascribed to things are not their essential properties but the result of relationships of people and things; their very materiality is potentially multiple and has a history. ${ }^{136}$ The mechanisms for ordering materials are often institutionally defined: libraries, art galleries and museums impose their own order on materials, whereas archives preserve the relationships inherent during their time of use. Nevertheless, they are equally products of human relationships and agency. The histories of how Mitchell's photographs have been handled in custodial institutions shows a trail of fixing meanings which have been fluid from their time of taking, and the power of contextual associations to change these. In saying this, the history of how Mitchell's photographs are categorised by institutions begins inside his own studio.

Despite the lack of documentation associated with his photographs, there are a few surviving clues to give some indication as to how Mitchell organised his own collections, and how his perceptions of his own work changed over time. The survival of this information has been more by individual chance than intent, as on entering custodial institutions his original negatives and storage boxes were for the most part destroyed along with any textual evidence they contained. There are differences between how he stored his prints and his negatives, and in part this may relate to how the different forms are used - negatives for production and prints for viewing, selection and display. Some of his negatives were stored chronologically in their order of creation, though most were stored by subject in an order he constructed while in his studio.

According to surviving box-labels, Mitchell separated his topographic from his Aboriginal negatives, even when they were taken in the same region or town or at the same time. ${ }^{37}$ Thus, streetscapes of Southern Cross, a Western Australian town, were stored apart from photographs of Aboriginal people from the area. Why he did this is open to speculation, although as a commercial photographer it may have been the way clients asked for material as part of selecting work from viewing material in his studio. This separation by subject content has influenced the histories of the different parts of his negative collection since his studio closed, and their placement and contemporary management in custodial institutions.

One of the few formats to discipline free-floating photographic prints into a narrative structure is the photograph album. ${ }^{38}$ An album brings items which may have

35. Porteus 1931: plate VXIII.

36. Holtorf 2002: 64 .

37. These boxes are held in private collections. 
originally been seen as separate together into a new and deliberate order. Through a combination of a fixed order of viewing and accompanying captions, an album can lend insight into the values accorded to specific photographs by its creator and reveal meanings that emanate from relationships as a result of the chosen order of the album. Where albums created at different times by the same person survive, it becomes possible to see shifts in the meanings of the photographs between the albums over time.

Mitchell's work survives in a range of photograph albums created for commercial, official, and personal purposes. Two albums, one of the north-west, and one of Aboriginal people, appear to have been made by him for his own purposes, and provide evidence for some of his private conversations with his photograph collections. ${ }^{39}$ Through the relationships he constructed between photographs, these albums provide insights into how he saw at least parts of his work, rather than how his negatives were stored for practical retrieval, or his work interpreted by others. They also reveal how his views of his photographs changed over time and how they rest as aspects of his personal memory of both people and places.

Mitchell's personal album of the north-west contains only photographs that were taken by himself. ${ }^{40}$ In contrast to the way he stored his negatives, the overriding order of the album is chronological, and it mixes photographs of places, industries, and Aboriginal people across the pages. This, along with similar styles of photographic paper, means the album is likely to have been constructed close to the time of taking the photographs. Mitchell may have spent time making this album because these photographs had immediate personal meaning. It is possible that he stored these photographs in this way because of his own growing awareness of the marketplace for his work. He may have recognised that what he was taking was important, that few others were recording it in the same way or with similar quality, and that they therefore might gain in commercial value over time. Equally, Mitchell may have created this album because much of the subject matter he was photographing would have been unfamiliar to him and he may have wanted to record his northern adventures for his personal remembrance.

While many of Mitchell's extant photographs of Aboriginal people remain loose and dispersed across a range of collections, one surviving album lends insight into aspects of his way of seeing a subset of Aboriginal photographs. The album contains 109 photographs of Aboriginal people, but it differs from his northern album in several respects. ${ }^{41}$ There is a range of styles of photographic paper and the album includes photographs taken as speculative ventures and for specific commissions, over a period of nearly 20 years. Mitchell's photographs are placed alongside works by other photographers and over time the authorship of some of these has become confused with that of Mitchell, who was the likely supplier to various authors and publishers. ${ }^{42}$ Thus, the

38. Ryan 1997: 220; Spence and Holland 1991.

39. Langford 2001.

40. This album is privately owned, held in Perth Western Australia.

41. Western Australian Museum album 87/08.

42. For example in Porteus 1931 the author attributes to Mitchell photographs taken by others.

The album contains photographs taken by JT' Kilfoyle, a Kimberley pastoralist for whom he undertook some developing and printing, PK Freeman and Mary Durack. Letter Mitchell to Alice and Sid Tidswell, Claremont, WA, 23 February 1948. Australian Joint Copying Project Reel (AJCP) M2760 II/109. 
album becomes an indicator of people with whom he had contact, as well as demonstrating an underlying trade in photographs of Aboriginal people, of which he was part.

The variation in printing and photographic paper styles, and the range of photographers included, suggest that the album was created long after Mitchell's photographs were taken. Mitchell hints at this when he wrote to his sister in 1953 that the Governor wants to see my collection of Abo photos which I have mounted into an album'. ${ }^{43}$ It is highly likely that the album held in the WA Museum is the album to which Mitchell is referring. While it is unclear when this album was constructed, it appears to have been compiled once the photographs had 'become historical'. ${ }^{4}$ While some of the same images appear in both albums, they are used in different ways. A comparison of these albums provides the opportunity to explore how Mitchell reflected on and changed the meaning of his works over time.

While his northern album was ordered chronologically and geographically, his Aboriginal album involved rearranging prints by subject within the category of Aboriginal. The separation of his Aboriginal work may have occurred because he had time to reflect on the importance of changing political and cultural contexts. Equally, the placement of Aboriginal photographs into a separate album mirrored the way his negatives were stored, which in itself was likely a response to market demands for this specific subject matter.

Rather than providing a chronological or geographical context, Mitchell carefully ordered his Aboriginal photographs to emphasise their visual rhetoric and styles. He intentionally juxtaposed photographs to highlight particular facets of the photographs - for example to emphasise physique, or those containing strong perspective lines. At one level Mitchell may have seen that these photographs had 'become historical' during his own lifetime. From the way the album is constructed, it is equally likely Mitchell saw they had, over time, 'become aesthetic'. Whether he saw them as having 'become anthropological' is another issue, though as will be discussed, he himself used some in ethnographic contexts and he saw them as separate enough to have a series placed in the Western Australian Museum in 1913.

\section{Preserving the label 'anthropological'}

Decisions, which for the most part remain undocumented, are made at specific points in the lives of objects and determine the very survival of material. ${ }^{45}$ As Edwards writes of museums specifically, although the same applies to all custodial institutions, 'museums are, of course, actively involved in selection, classification and reclassification as essential mechanisms of truth production' ${ }^{46}$ Once photographs enter custodial institutions their meanings are framed simply by virtue of moving from representing the

\footnotetext{
43. Letter Mitchell to Alice and Sid Tidswell, Claremont, WA, 12 April 1953. AJCP M2760 II/133.

44. While the act of photographing creates something that is instantly historical by virtue of the moment in which the photograph is created has passed, in this context, the term 'historical' refers to the passing of decades rather than seconds.

45. See for example Holtorf 2002 or Sassoon 2001 for discussions of the consequences of an object being defined as worthy of preservation.

46. Edwards 2001: 195.
} 
present to representing the past - that is, they 'become historical'. Materials are overlain with the "clerical apparatus ${ }^{47}$ of a subject scheme which is critical in framing the way photographs are retrieved and used. Writing labels on materials has long lasting consequences as the practices of custodial institutions fix what has, up until this point in the lives of objects, been more fluid. As such, this process of fixing categories becomes a sign of institutional understandings of the material under their care, and as has already been discussed, multiple originals of Mitchell's photographs were categorised differently according to the context in which they were found. Once in custody, the history of Mitchell's archive reveals how its integrity and history has been overwritten by raw institutional practice.

Mitchell's studio collections are widely scattered across private and institutional collections with the only apparent logic of its dispersal being that of how his collections were originally organised in his studio. Prints appear in a range of government and private collections, as surviving evidence of the widespread distribution of multiple originals of his work. About 100 negatives, mostly of Aboriginal people and Queensland landscapes, which were purchased privately through an auction in England from an untraced Belgian owner in the 1990s, remain in private ownership. A similar cache of negatives was purchased in Perth on the open market in the early 1990s and is now in private hands. His personal album of north-west photographs is in private hands without provenance, passed to the current owner by a relative whose relationship to Mitchell has yet to be traced. A group of topographical negatives and prints, which includes some personal snapshots, was purchased by an individual after advertisements for sale were placed in the Perth press in the 1970s. ${ }^{48}$ This collection was lent for copying to the State Library in Western Australia, then on-sold to a commercial organisation, only to be returned to a public institution when there was a perceived threat to its long term preservation due to changes in company ownership. There are also substantial collections of his work in the National Library of Australia, the Royal Geographical Society, London - donated by V Scott O'Connor following a visit to Westerr Australia - and prints returned to Western Australia from the Agent General's collection in London.

The largest cache of several hundred of Mitchell's topographical negatives found its way into the State Library in Perth prior to his death in 1959, where they have yet to made publicly accessible. ${ }^{49}$ Thus at its rawest, institutional practice means this material remains invisible. The original negative boxes along with Mitchell's own labels, which were the records of his storage order, were destroyed by the custodial institution, thus rendering this once ordered series a free-floating collection of negatives. Another significant part of his archive, including a large number of loose prints, his guard book of his early newspaper publications, Masonic Lodge cards, and his album of Aboriginal pho-

47. Sekula 1989: 352 .

48. It is likely this occurred after the death of his wife in 1972.

49. They are part of a homogenous collection of about 100,000 glass negatives which remain undocumented, inaccessible and effectively unknown. Their identity as Mitchell's negatives has been subsumed under the authority of the collector, Dr Battye. In 1997, this portion of the glass negative collection was seen as a low priority for being made more accessible. Team Leader, Battye Original Materials Team, pers comm 12 Sptember 1997. 
tographs, was passed to the Western Australian Museum many years after Mitchell's death by the son of his former neighbour. Since being donated to the Museum, this part of his archive has undergone a further series of transformations through internal practices that have had a long-term effect on the future research potential of this material.

The keenness of the Western Australian Museum to collect photographs is documented from the late 1890s. Almost since its inception, the Museum had employed a collector to gather natural history specimens, particularly from the north of Western Australia. John Tunney often took field photographs of the specimens, and also photographed Aboriginal people though apparently with limited success. Commissioning Tunney to take field photographs is indicative of the local awareness of the rising importance of collecting documentary photographs for the museum collections.

By the time 'photographs' appeared as a separate heading in its annual report in 1901/02, about 294 negatives were recorded in the Museum stock. The subjects of these negatives included 'birds and nests', 'aborigines', 'museum', 'West Australian scenery', 'Kimberley', 'caves', and 'miscellaneous'. ${ }^{50}$ The photographers remain for the most part anonymous. While there was a keenness to commission and collect photographs, how they were understood by the Museum can be deduced from the manner in which they were described in accession registers. The earliest entries for photographs in 1903 were as perfunctory for objects as for photographs. Its entry of ' 9 photographs' from C Bader falls between 40 casts of carvings from French Caves, and two glass spearheads. ${ }^{51} 1910$ seemed a better year for Museum documentation of photographs with individual descriptive entries for each of eight photographs of Aboriginal people donated by the photographer W Kretchmar and 14 donated by Gerald Hill. However, only a few years later the entries returned to their prior brevity with photographs relegated once again to a status below that of objects, if accession descriptors are used as a sign of museum thinking. Eighteen photographs by Mitchell were received by the Museum on 18 August 1913, and their register descriptions can be seen in one sense as a preface to how the Museum later undervalued the large donation of Mitchell's materials. The four entries in the register prior to the photographs were individual descriptive entries for spears: one with a head made of brown earthenware, one with a heavy wooden head fitted to lighter shaft, one with a carved head and shaft in one piece, and one carved ornamental head and shaft in one piece. The next entry, no. 5534 is for ' 18 photographs of Australian Aborigines. 52

While collecting of material continued through the 20th century, it was only with the 1960s mineral booms that there was a new phase of professionalisation in the Museum's curatorial activities. In the absence of formal documentation, the Western Australian Museum collecting policies of the 1970s in relation to photographs can only be deduced from correspondence. For example, in 1971 a curator explained to a potential donor that 'In general we do not keep documents and photographs at the Museum, preferring to pass them on to the Battye Library. ${ }^{53}$ In 1974 the ideas relating to collect-

50. Western Australian Parliamentary paper 1901/2.

51. Western Australian Museum undated a.

52. Western Australian Museum undated b.

53. Letter 12 January 1971 Western Australian Museum Photographs - General, Western Australian Museum file 283/7/1. 
ing appear to have shifted as another curator wrote 'These old photographs are very welcome as they can be re-photographed and blown up for use in backgrounds for displays. ${ }^{, 54}$ Only a couple of years later it was stated that 'At the Museum, we place our emphasis on the collection of objects associated with our State's history and documents and photographs are dealt with by the State Archives' ${ }^{55}$ In the absence of formal policies, these letters serve as markers of how photographs were understood in the museum at this time. They show a picture of internal confusion as to whether the institution was or was not collecting photographs and an ambivalence as to what purpose they may eventually serve.

While at one level custodial institutions such as museums, libraries and archives imply secure long term preservation of objects and documents, at another level this does not necessarily apply to the ephemeral and contextual relationships that are critical to ensuring the preservation of meanings. The lives of Mitchell's materials once in custodial institutions are in themselves instructive as to the influential role institutions play in shaping meaning. Once accepted into the Western Australian Museum in 1987, Mitchell's 'archive' was fractured by subject and form showing little respect for the importance of its provenance. This may be due to the general lack of sensitivity of museum practice towards preserving archival meaning, or the emerging political contexts raising questions about the management of materials relating to Aboriginal people. ${ }^{56}$ However, the fragmentation of Mitchell's archive is also an indicator of the value placed on photographs as a form where individual content is seen as paramount over recognising the archival value of groups of related photographs. The life that Mitchell's archive follows within the Museum begs the question as to whether multiformat archaeological assemblages from the same site would be treated in a similar manner. ${ }^{57}$

Once in the Museum, different parts of Mitchell's archive followed different trajectories. Defined by their content as 'social history' and therefore outside institutional collecting parameters, the loose topographic and industrial photographs were transferred to the State Library, along with all other documentary and associated ephemeral material. Once in the State Library the remnants of the archive continued to be fractured and disseminated according to standard library practice which, like museum practice, values the individual object above less tangible archival relationships. The photographs were transferred to the Pictorial collection, the guard-book to the Manuscripts collection, and the Lodge cards to the Ephemera collection. ${ }^{58}$ The integrity of the archival anchor was undermined through the separation and movement of materials

54. Letter 11 December 1974 Western Australian Museum Photographs - General, Western Australian Museum file 283/7/1.

55. Letter 25 June 1976 Western Australian Museum Photographs - General, Western Australian Museum file 283/7/1.

56. Australian Library and Information Association 1995 and Museums Australia 1996.

57. Karskens 2002.

58. Since the research for this paper was completed, Mitchell's Lodge cards in the State Library of Western Australia have undergone a new phase of life. All the non-Western Australian material has been transferred to other organisations, and Mitchell's Western Australian lodge cards are now part of a general Freemasons listing. Thus their provenance in relation to Mitchell has now been entirely destroyed. 
within and between the custodial institutions. Thus, one consequence of becoming historical' is that Mitchell's archive lost its provenance and integrity to become a dislocated series of collections.

Amongst the material donated to the Museum was the aforementioned album containing photographs of Aboriginal people. While parts of the Mitchell archive 'became historical' through transfer to the State Library, this album was separated from the rest of the material and retained within the Museum. No doubt simply because of its subject content the album was transferred to a department whereby its label was written as 'anthropological', and joined 18 other photographs by Mitchell recorded in the Ethnological register as being received by the Museum in $1913 .{ }^{59}$ As has already been discussed, these photographs were not taken with anthropological intent but for commercial ends, and thus their description as 'anthropological' does not necessarily reflect their meanings at the moment of production. This is not to say that the meanings of photographs remained fixed for the photographer during his own lifetime. As has already been discussed, over time, and as these photographs became historical, Mitchell saw them as being aesthetic and distinctly separate from his topographic and industrial prints. As will be seen, he also saw them as anthropological through his own use of them in his private exhibition. However, the labelling of the album as 'anthropological' at its point of preservation privileges the patterns of consumption of multiple originals of some of the photographs and the trajectories of some of their lives over their contexts of production. This in itself raises questions as to the fluidity of photographic meanings which then become fixed at a particular moment by institutional practice.

\section{Exhibiting anthropology}

Relationships between collecting and documentation practices in custodial institutions and the research potential of material are close. How material is organised and retrieved becomes the first citation in a new cycle of 'institutional meaning-making', of which another component is exhibition practice. With the organisation of material culture as another expression of a way of seeing the world, Mitchell's photographs of exhibitions of Aboriginal artefacts provide evidence of uses of his photographs in exhibitions where other records are scant. Thus these photographs present the opportunity to explore a double layer of semiotic meaning. ${ }^{60}$ Equally, his photographs have been used in exhibitions which cover a long period of time, and which reflect the labels written on the materials after they entered the Museum.

Alongside his photographic work, Mitchell was an amateur collector of Aboriginal and Malaysian artefacts, geological specimens and, in later life, stamps. Though he may have originally collected these for personal interest or to supplement his photographic record as to the 'state' of Aboriginal culture, in later life he was aware that they had accrued monetary value. He also recognised the exhibition potential of his own collection, though this may simply be a natural extension of his personal narrative of possession. In a 1913 letter he provides the context for a photograph of the interior of his house: 


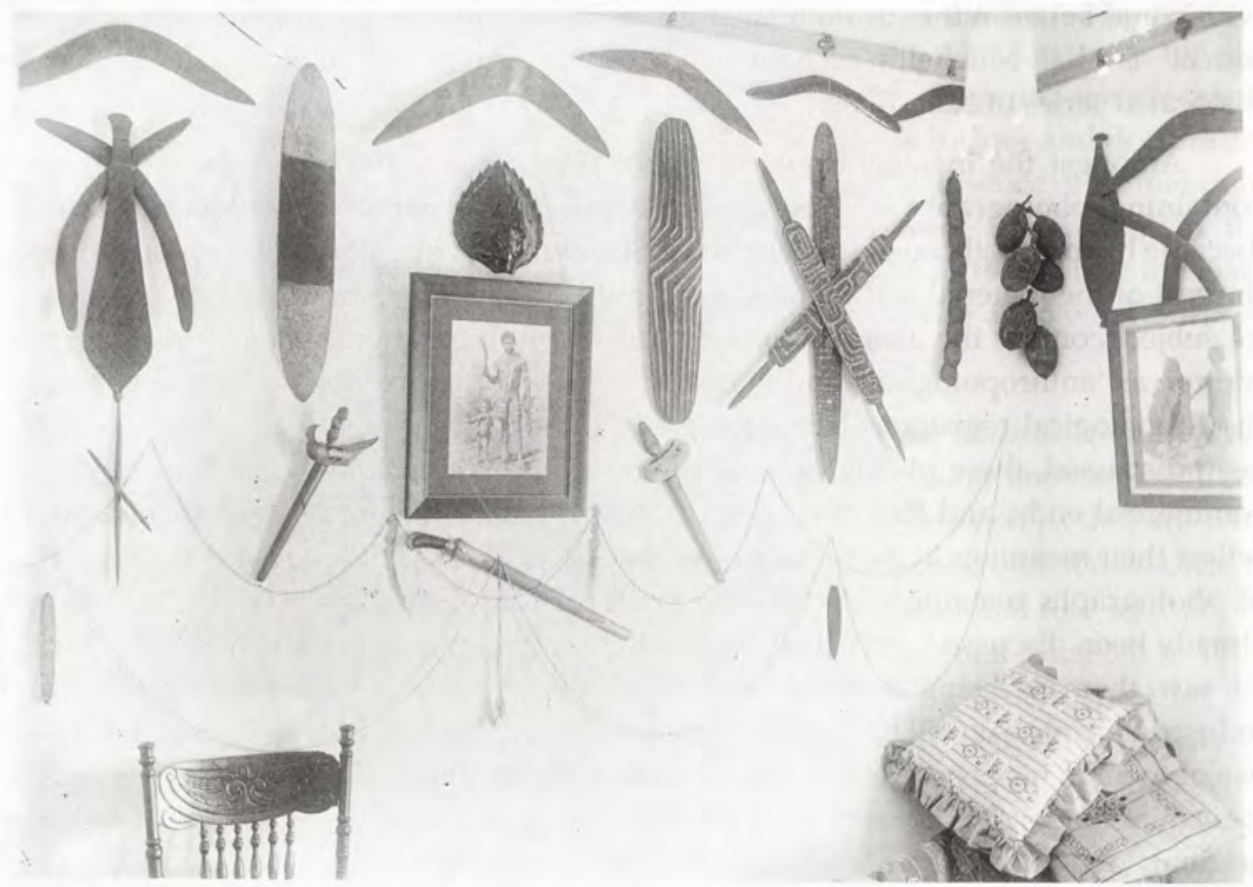

Figure 7 EL Mitchell, undated. Interior of Mitchell's house showing his photographs. Battye Library, State Library of Western Australia

Since you were here I have built a house at Mt Lawley \& have fixed up a room for when you take your next trip to W.A. ... have likewise added a den or smoke room or as the wife calls it 'the museum' as I'm filling it with curios that have not been unpacked for years. ${ }^{61}$

How Mitcheil displayed his ethnographic collections in his personal 'museum' lends credence to ideas about difference between the 'primitive' and the 'civilised' contained within his broader photographic work, and is reflected within its physical organisation. One photograph of his 'museum' which was likely to have been taken to send to his family in England, shows his photographs within a homogenised artistic display of artefacts from Malaysia and Northern Australia (Figure 7). Within the room, the objects juxtaposed against the chintz of empire style furniture reinforce his notions of the 'primitive' reflected in his photographs of Aboriginal people. The internal separation of his museum from the mantelpiece display of his family and Freemasons photographs is another sign of his desire to distinguish himself from 'the other'. Thus, the politics contained within his oeuvre and his studio organisation - framing people as types, and the separation of Aboriginal people from other social and cultural engagement - is replicated in his own private ethnographic exhibition.

In a more artifact-rich and artistic exhibition in the home of a significant private collector, West, the arrangements likewise aestheticise objects from different parts of

61. Letter Mitchell to E.J. Brady, Perth, WA, 8 January 1913. National Library of Australia, EJ Brady collection MS 206/1/139. 


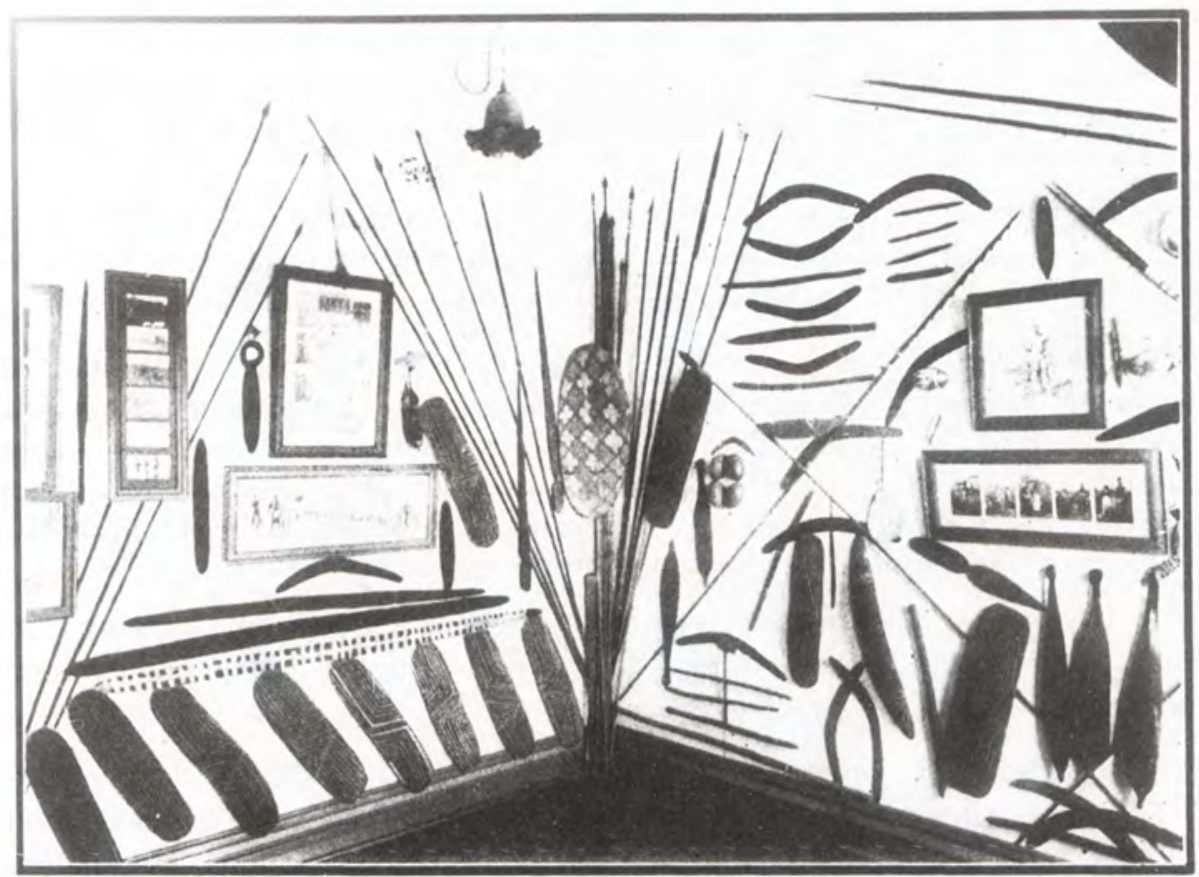

A FINE COLLECTON OF NATIVE W EAPONS AND OTHER CURIOS AT THE PESIDENCE OF MR AND MRS. WEST, GUILDFURD.

Figure 8 EL Mitchell. 'A fine collection of native weapons and other curios at the residence of Mr and Mrs West, Guildford'. Western Mail 3 September 1915

Australia (Figure 8). In this context, while Mitchell's photographs had the potential to add informational value to the exhibition, their function remained decorative. Mitchell's photograph of West's exhibition was published in the Western Mail around the same time ethnographic displays were being re-organised at the Western Australian Museum, and therefore one can see the replication of private and public exhibition practices.

Exhibitions were one key function of the fledgling Western Australian state Museum. Despite an ongoing lack of funding, this was an activity that was taken seriously. However, after many decades of limited funds, David Ride's initial observations of the Museum in 1957 included noting somewhat unsympathetically that the displays 'combine many of the worst aspects of nineteenth century clutter with the best of modern practice'. ${ }^{62}$ The museology collection held in the Museum library attests to successive directors being up to date with international museum literature while residing on the edge of Empire, and directors were also active in debating museum trends in the newspapers. ${ }^{63}$ Determined to maintain international exhibition practice, it was

63. Newspaper clipping books, Western Australian Museum Archives. 
noted in the Trustees minutes of 1910 that during his sojourn in Perth as part of his ethnological expedition,

The Director reports that Prof A.R. Brown has spent six weeks in examining and re-arranging the exhibits in the Ethnological Gallery, and was to write a guide to the collections. ${ }^{64}$

There is no record of this guide, though in 1912 it was reported that the 'Ethnological Gallery has been entirely re-arranged by $\mathrm{Mr}$ Glauert in the manner advised by $\mathrm{Mr}$. Alfred R. Brown. ${ }^{65}$ In the $1915 / 16$ annual report of the Museum it was noted that:

The Ethnological Gallery is now exclusively Australian in character, Western Australian specimens being utilised wherever possible. Complete series have been prepared to illustrate the daily life, industries, manners, customs, arts and religious beliefs of the primitive aboriginal inhabitants of this State. The educational and instructive value of the typical specimens exhibited has been amplified by means of numerous photographs and descriptive labels. ${ }^{66}$

It may be a sign of limited resources, or a lack of frequency in changing exhibitions, more than a lack of sense of recording its own activities that no photographs of these early exhibitions have yet been traced.

With museums described as a cultural 'add-on made possible by the presence of social and economic surplus', ${ }^{67}$ it was only with the mineral booms of the 1960 s and the 1970s that the Museum budget began to expand and new exhibitions could be imagined. Keen to achieve international exhibition standards, the Museum saw that 'a basic hurdle to be overcome is the almost total ignorance of the subject [Aboriginal culture] and the resultant prejudice based upon this ignorance ${ }^{68}{ }^{68}$ To this end, an important imperative was to reverse the trend that 'Almost all Museum displays of an ethnographical nature eventually become centred upon things and not people. ${ }^{69}$ The groundbreaking Patterns of life exhibition ${ }^{70}$ reversed this trend, and photographs were used as a key representational tool about human activity. While many of the photographs in this exhibition derived from anthropological fieldwork in the 1940s and 1950s, Mitchell's photographs of recreated cultural practices were used. In providing functional and social contexts for the artefacts, enlarged photographs were placed in the backs of the cabinets.

Since its incorporation into the Anthropology collection of the Museum, Mitchell's photographs from the Aboriginal album have also been used in the Museum's most recent Indigenous exhibition, Katte Dinoong, which includes ethnographic, historical and contemporary stories. With the introduction of digital technology and thus mosaicstyle enlargements, their placement in the exhibition shifts from their function as informative backdrop in Patterns of life to front of house wallpaper to provide fleeting contextual decoration. In line with its institutional accessioning practices, Mitchell's

64. Trustees of the Western Australian Museum 8 January 1910.

65. West Australian, 6 September 1912.

66. Western Australian Museum 1915/16.

67. Harris 1989: 133.

68. Internal memo 5 April 1972, Anthropology displays Western Australian Museum file 74/72.

69. Internal memo 5 April 1972, Anthropology displays Western Australian Museum file 74/72.

70. Lofgren: 1975. 
photographs used in this exhibition remain enmeshed in the broader discourse of anthropology rather than being returned to their historical contexts. Captions are invented to add context to the stories contained in the exhibition, but they overwrite the original intent of the photographer. ${ }^{71}$

\section{After-thoughts}

Mitchell's photographs 'became anthropological' as a consequence of the relationships between the ideas they contained and the context of contemporary political and cultural agendas. As Edwards writes in relation to photographs, 'material in circulation is active in the meaning making of culture, ${ }^{72}$ and Mitchell's photographs have also played an active role in shaping attitudes towards Aboriginal people according to the contexts in which they have been placed, preserved and used. During the ebb and flow of the long lives of Mitchell's photographs, meanings changed for the photographer himself, and institutional practice has been an active agent in the processes of other forms of making meaning. As Roslyn Poignant writes 'a single image that is separated from its historical anchorage becomes temporarily free; it 'floats' and invites objectification, which opens the way to uses that fetishise and stereotype'. ${ }^{73}$ The separation of a single album from the archive of related photographs and other forms of materials resulted in a new label being written. Its placement in the Museum context now limits the viewer to seeing the album within single stereotypical frame as 'anthropological', and its relationship to the broader context of Mitchell's oeuvre has been rendered invisible.

This cultural biography shows the way that meanings and values are accumulated and transferred through human activity. However, cultural institutions have a particular responsibility to ensure that the meanings contained within and surrounding objects retain their potential fluidity and complexity. A specific challenge in managing photographs is to ensure that their status as objects is given equal weight compared with other forms of material culture held in museums, libraries or archives. The power of cultural institutions lies in the capacity to release the research potential of photographs by documenting the complexity of the materials. However, as this study shows, in the process of 'becoming anthropological', Mitchell's photographs of Aboriginal people have lost their history.

\section{References}

\section{Primary sources}

Ride, WLD 1957, The Western Australian Museum in September 1957, Trustees Correspondence, Western Australian Museum file D250/71/1.

Trustees of the Western Australian Museum 1910, Minutes of the Western Australian Museum, State Records of Western Australia Acc 948/6.

Western Australian Museum 1901/2, 'Annual report', Western Australian Parliamentary paper A18/1902.

Western Australian Museum 1915/16, Annual report of the WA Museum unpublished.

71. Moran 2002: 43-49.

72. Edwards 2001: 39.

73. Poignant 1996: 162. 
Western Australian Museum undated b, Register of Ethnological specimens 4096-9587. Western Australian Museum undated a, Black register.

\section{Secondary sources}

Anonymous 1920, Western Australia: its early vicissitudes, romantic awakening, development, and progress, Government Printer, Perth.

Aird, Michael 1993, Portraits of our elders, Queensland Museum, Brisbane.

Australian Library and Information Association 1995, Aboriginal and Torres Strait Islander protocols for libraries, archives and information services, ALIA, Canberra.

Born, Georgina 1998, 'Public museums, museum photography and the limits of reflexivity', Journal of Material Culture 3(2): 223-54.

British Association 1914, Handbook and guide to Western Australia: prepared for the members of the advance party of The British Association for the Advancement of Science on the occasion of their visit to Perth and the South-Western portion of the State, under the direction of the Local Publications Committee, Government Printer, Perth.

Browne, GS 1929, Australia: a general account: history: resources: production: social conditions, Thomas Nelson and Sons, London.

Edwards, Elizabeth 1992, Anthropology \& photography 1860-1920, Yale University Press in association with the Royal Anthropological Institute, London.

- 1997, 'Ordering others: photography, anthropologists and taxonomies' in In visible light: photography and classification in art, science and the everyday, Chrissie Iles and Russell Roberts (eds), Museum of Modern Art, Oxford: 54-68.

-2001, Raw histories: photographs, anthropology and museums, Berg, Oxford.

Geary, Christraud M, and Virginia-Lee Webb 1998, Delivering views: distant cultures in early postcards, Smithsonian Institution Press, Washington.

Gooding, Janda 1987, Western Australian art and artists 1900-1950, Art Gallery of Western Australia, Perth.

Gosden, Chris and Yvonne Marshall 1999, 'The cultural biography of objects', World Archaeology 31(2), 1999: 169-178.

Gray, Geoffrey 1997, ' $\mathrm{Mr}$ Neville did all in [his] power to assist me': AP Elkin, AO Neville and anthropological research in northwest Australia, 1927-1928', Oceania 68: $27-46$.

— 1998, “(This often) sympathetic collaboration: anthropologists, academic freedom and government 1927-1952', Humanities research 2: 37-60.

Haebich, Anna 1988, For their own good: Aborigines and government in the southwest of Western Australia, 1900-1940, University of Western Australia Press, Nedlands.

-2000, Broken circles: fragmenting indigenous families 1800-2000, Fremantle Arts Centre Press, Fremantle.

Harris, Neil 1989, 'Museums: the hidden agenda' in Cultural excursions: marketing appetites and cultural tastes in modern America, Neil Harris (ed), University of Chicago Press, Chicago: 132-47.

Hodge, Pamela 1992, 'Daisy Bates and her aboriginal children': the personal and social origins of the construction of myth', Honors thesis, Murdoch University.

Holtorf, Cornelius 2002, 'Notes on the life history of a pot sherd', Joumal of Material Culture 7(1): 49-71. 
Hutchison, David (ed) 1995, A town like no other: the living tradition of New Norcia, Fremantle Arts Centre Press, Fremantle.

Karskens, Grace 2002, 'Engaging artefacts: urban archaeology, museums and the origins of Sydney', Humanities research 9(1): 36-56.

Kopytoff, Igor 1986, 'The cultural biography of things: commoditization as process' in The social life of things: commodities in cultural perspective, Arjun Appadurai (ed), Cambridge University Press, Cambridge: 64-91.

Langford, Martha 2001, Suspended conversations: the afterlife of memory in photographic albums, McGill Queens University Press, Montreal.

Leslie, Norman 1993, 'Black and white: photographic imagery and Aboriginality', Australian Journal of Communication 20(2): 79-96.

Lofgren, ME 1975, Patterns of life, Western Australian Museum, Perth.

Mjoberg, Eric 1915, Bland vilda djur och folk i Australien, Albert Bonniers, Stockholm.

Moran, Rod 2002, 'Paradigm of the postmodern museum', Quadrant Jan/Feb 2002: 43-49.

Museums Australia 1996, Previous possessions, new obligations: a plain English summary of policies for museums in Australia and Aboriginal and Torres Strait Islander peoples, Museums Australia, Melbourne.

Pinney, Christopher 1997, Camera Indica: the social life of Indian photographs, Reaktion Books, London.

Poignant, Roslyn 1993, 'The photographic witness?', Continuum 6(2): 178-206.

Poignant, Roslyn with Axel Poignant 1996, Encounter at Nagalarramba: National Library of Australia, Canberra.

Poole, Deborah 1997, Vision, race and modernity: a visual economy of the Andean image world, Princeton University Press, Princeton.

Porter, Gaby 1989, 'Economy of truth: photography in museums', Ten 8 34: 20-33.

Porteus, Stanley D 1931, The psychology of a primitive people: a study of the Australian Aborigine, Longmans, Green \& $\mathrm{Co}$, New York.

Ryan, James 1997, Picturing empire: photography and visualization of the British empire, Reaktion Books, London.

Sassoon, Joanna 1999, 'EL Mitchell and the imaginary Broome', History of Photography, 23(2): 149-156.

- 2001a, 'An archaeology of memory: a cultural biography of photographs of EL Mitchell 1900-1930', PhD thesis, University of Western Australia.

- 2001b, 'Chasing phantoms in the archives - the Australia House photograph collection', Archivaria 50: 117-124.

- 2004, 'The politics of pictures: a cultural history of the Western Australian Government Print photograph collection', Australian Historical Studies, 123: 16-36.

Schwartz, Joan M 1996, “We make our tools and our tools make us": lessons for photographs from the practice, politics and poetics of diplomatics', Archivaria 40: 40-74.

Sekula, Allan 1989, 'The body and the archive', in The contest of meaning, Richard Bolton (ed), MIT Press, Cambridge: 343-88. 
Spence, Jo and Patricia Holland 1991, 'Introduction', Family snaps: the meanings of domestic photography, Virago, London: 1-14.

Tagg, John 1988, The Burden of representation: essays on photographies and histories, Macmillan, London.

Tilbrook, Lois 1983, Nyungar traditions: glimpses of Aborigines of south-western Australia 1829-1914, University of Western Australia Press, Nedlands.

Watson, EL Grant 1930, With the Australian Aborigines, George Philip \& Son, London.

Western Australia, Immigration and Tourist Department 1912, The Handbook of Western Australia: an official publication for the information of commercial men, tourists and immigrants, WA Government Printer, Perth.

White, Isobel 1980/81, 'Mrs Bates and Mr Brown: an examination of Rodney Needham's allegations', Oceania 51: 193-210.

- (ed) 1985, The native tribes of Western Australia, National Library of Australia, Canberra. 